\title{
Diversity of Morphological Traits and Glucosinolate Composition in Backcross Progenies of Brassica Rapa L. × Eruca Vesicaria (L.) Cav. Hybrids
}

Aiko Kaminishi ( $\square$ akaminishi@tbz.t-com.ne.jp )

Kanagawa Agricultural Technology Center https://orcid.org/0000-0001-7939-7984

Fumika Miyohashi

Miura Peninsula District Office of Kanagawa Agricultura Technology Cnter

Nobuhiro Kita

Nihon University: Nihon Daigaku

\section{Research Article}

Keywords: Arugula, Brassicaceae, Functional component, Intergeneric crossing

Posted Date: December 17th, 2021

DOI: https://doi.org/10.21203/rs.3.rs-1163106/v1

License: () (i) This work is licensed under a Creative Commons Attribution 4.0 International License. Read Full License 


\begin{abstract}
Breeding at both interspecific and intergeneric levels is an effective method for expanding genetic variation of cruciferous crops; however, few commercially accepted varieties have been released because of difficulties in generating fertile progenies. We employed backcross strategy to introduce Eruca vesicariaspecific characteristics into Brassica rapa and successfully obtained four $\mathrm{BC}_{1} \mathrm{~F}_{1}$ lines that showed a wide range of diversity of morphological traits and glucosinolate (GSL) composition. Thus, leaf shape, anthocyanin coloration, glucoraphanin content, and red petal veins were found to be inherited mainly from $E$. vesicaria, though most of the morphological characteristics and GSL composition were inherited from intergeneric $F_{1}$ plants. Since all $B_{1} F_{1}$ lines showed post-fertilization barriers, backcrossing with $B$. rapa was performed and $\mathrm{BC}_{2} \mathrm{~F}_{1}$ progenies were successfully obtained, which showed diverse morphological characteristics and GSL composition as well as higher regeneration potential. These results suggest that widening of genetic diversity of $B$. rapa can be achieved through successive reciprocal backcrossing of $B$. rapa $\times$ E. vesicaria hybrids with $B$. rapa.
\end{abstract}

\title{
1. Introduction
}

Application of both interspecific and intergeneric crossing in plant breeding has dramatically expanded genetic variation that encompasses functional metabolites, disease resistance, and morphological characteristics that attract consumer and commercial market interests. Spinach mustard (Brassica rapa var. perviridis L. H. Bailey, a synonym of $B$. rapa L.; AA, $2 n=20$ ), an important leafy vegetable widely cultivated year-round in Japan, includes komatsuna, mizuna, chinese cabbage, and turnip that comprise hundreds of varieties with a narrow genetic and secondary metabolite variation. Therefore, innovative improvement in metabolic components that influence taste and flavor of these vegetables is expected (Velasco et al. 2017; Friedt et al. 2018).

Arugula (Eruca vesicaria (L.) Cav.; syn. E. vesicaria Mill.; EE, $2 n=22$ ), a delicious leafy vegetable from the Brassicaceae family, was introduced into Japan in 1990 s and its sesame-like flavor impressed Japanese consumers (Kim et. al. 2004). It contains erucin (4-methylthiobutyl isothiocyanate) and sulforaphane (4methylsufinylbutyl isothiocyanate) that belong to the methyl-sulfinyl-type isothiocyanates. Ingestion of erucin and sulforaphane is known to induce phase II detoxifying enzymes that control carcinogenesis in humans (Bell and Wagstaff 2014, 2019). As B. rapa does not produce glucosinolates such as erucin and sulforaphane (Ishida et al. 2014; Osada and Aoyagi 2014), interspecific crossing between B. rapa and E. vesicaria might result in obtaining unique leafy vegetables with functional ingredients and a distinctive sesame-like flavor characteristic to arugula.

Interspecific or intergeneric backcross breeding within the Brassicaceae family is theoretically expected to give three lines in the second generation: an alien gene(s) introgression line (AGIL) as a result of homologous recombination during meiosis, a monosomic alien chromosome-addition line (MAAL) that contains additional heterochromosomes, and a monosomic alien chromosome substitution line (MASL) in which heterogeneous chromosomes are substituted (Kaneko and Bang 2014). Thus, these offspring lines are expected to contain not only various genome composition but also novel, unexpected metabolic pathways acquired through "genomic shuffling."

Intergeneric crosses between $B$. rapa and $E$. vesicaria were obtained using various combinations of ovule and pollen parents among different varietal groups (Mizushima, 1950a, b; Agnihotri et al. 1990; Matsuzawa et al. 1999). Some of these crossings rendered functional hybrids, whereas most of the intergeneric crosses resulted in no progenies (FitzJohn et al. 2007; Kaneko et al. 2009). Mizushima (1950a, b) successfully performed intergeneric crossing between $B$. rapa as the ovule parent and $E$. vesicaria as the pollen parent to generate haploid and double haploid progenies, though he could not establish stable breeding lines. Recently, we have succeeded in obtaining intergeneric hybrids using the same crossing combination (Kaminishi et al. 2017). Interestingly, the resultant progenies had novel characteristics such as red-blotched petals with red veins as well as a series of glucosinolate (GSL) compounds that both parents produce.

In this study, we employed backcross strategy to introduce $E$. vesicaria-specific characteristics into $B$. rapa using its intergeneric $\mathrm{F}_{1}$ as a cross parent, and the morphological traits and GSL composition of the progeny were analyzed for genetic variation range.

\section{Materials And Methods}

\subsection{Plant materials, embryo rescue, and growth conditions}

Brassica rapa (var. perviridis; Misaki series, SAKATA SEED Corp, Yokohama, Japan.) and Eruca vesicaria (var. Rucola, KANEKO SEEDS Co., Ltd., Maebashi, Japan) were used as the recurrent and the nonrecurrent parent, respectively, both of which being fixed line, open-pollinated cultivars. Backcrossing was carried out according to Kaneko and Bang (2014) (Fig. 1) using intergeneric hybrids of B. rapa and E. vesicaria generated in 2017 (Kaminishi et al. 2017 ).

Siliquae were harvested 35 days after artificial pollination and subjected to embryo culture as follows: siliquae were disinfected with $70 \%$ ethanol for 1 min and subsequently immersed in $0.7 \%$ sodium hypochlorite for $5 \mathrm{~min}$ at room temperature. They were washed with sterilized water twice. Immature embryos

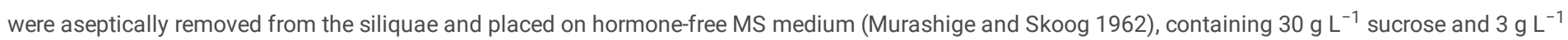
gellan gum at $\mathrm{pH}$ 5.8. Embryos were then incubated at $25^{\circ} \mathrm{C}$ under the 16 -h light cycle provided by fluorescent bulbs. When the embryos regenerated shoots and became ca. $5 \mathrm{~cm}$ high, they were transplanted in plastic pots filled with sterilized clay soil supplemented with N:P:K $=130: 700: 160 \mathrm{mg} \mathrm{L}{ }^{-1}$ and grown in a growth chamber at $15^{\circ} \mathrm{C}$ under the 12 -h light cycle provided by fluorescent bulbs. As the shoots grew ca. $25 \mathrm{~cm}$ high, leaves were harvested for glucosinolate and morphological trait analysis. The plants were then subjected to vernalization by growing in a growth cabinet maintained at $10^{\circ} \mathrm{C}(\mathrm{day})$ and $5^{\circ} \mathrm{C}$ (night) under the 10/14-h light regime, respectively, until bolting started. After bolting, plants were returned to a growth chamber and further grown at $15^{\circ} \mathrm{C}$ under $12-\mathrm{h}$ fluorescent light conditions.

\subsection{Pollen tube growth observation}

Page 2/12 
Pollen of $B$. rapa was used to pollinate $\mathrm{BC}_{1} \mathrm{~F}_{1}$ stigmas after emasculation. After $48 \mathrm{~h}$, pistils were fixed with the Farmer's solution and treated $2-3 \mathrm{~h}$ with $1 \mathrm{M}$ sodium hydroxide solution. They were subsequently stained with $0.1 \%$ aniline blue solution for 30 min to check for callose formation under a fluorescence microscope with UV excitation (Zeiss Axioskop 2 plus; Carl Zeiss AG, Oberkochen, Germany). Ten samples were observed per a regenerant.

\subsection{Glucosinolate (GSL) analysis}

GSL content of regenerated plants was profiled using the method described by Ishida et al. (2011). One leaf was taken from each 25 -cm tall plant. Leaves were freeze-dried and ground with mortar and pestle. One millimolar sinigrin (Tokyo Chemical Industry Co., Ltd., Tokyo, Japan) was added to a powdered sample as an internal standard and extraction was performed in $80 \%$ methanol at $75^{\circ} \mathrm{C}$. The extracts were adsorbed on Sephadex A-25 (Amersham Biosciences AB, Uppsala, Sweden), packed in a mini column, desulfated using sulfatase, and then eluted. GSL content was then analyzed with a HPLC system (LC-20 System; Shimadzu Corporation, Kyoto, Japan) using an Inertsil ODS-2 column (2.1 × $150 \mathrm{~mm}$, GL-Science Co., Ltd., Shinjuku, Japan). The operating conditions were as follows: column temperature $30^{\circ} \mathrm{C}$, ultraviolet detection wavelength $229 \mathrm{~nm}$, flow rate $1.5 \mathrm{~mL} \mathrm{~min}^{-1}$, and sample injection amount $20 \mu \mathrm{L}$. The mobile phase consisted of ultra-pure water as the solution A and $20 \%$ acetonitrile aqueous solution as the solution $\mathrm{B}$. Initial composition was $99 \%$ solution A for the first min, gradually changing to $99 \%$ solution B by a linear gradient from the 1 st to 21 st min. GSL content of broccoli (B. oleracea var. italica) flower bud, turnip (B. rapa subsp. rapa), rootstalk, cabbage (B. oleracea var. capitata), spinach mustard (B. rapa var. perviridis L.H. Bailey) leaves, arugula ( $E$. vesicaria L. Cav) leaves, and rape (B. napus) seeds were used to determine types of GSL compounds, according to the correspondence to chromatogram peaks. The amount of each GSL was then calculated using the response factor for sinigrin (Ishida et al. 1995, 2011; Osada and Aoyagi 2014).

\subsection{Evaluation of morphological parameters}

The following morphological traits were recorded for each regenerated $25 \mathrm{~cm}$ tall flowering plant: presence or absence of pungency, leaf sesame-like scent, leaf shape, pubescence, and leaf anthocyanin coloration. Both pubescence and anthocyanin coloration are known to be characteristic for $E$. vesicaria but not for $B$. rapa. In theory, $\mathrm{F}_{1}$ should be an amphihaploid/diploid and $\mathrm{BC}_{1} \mathrm{~F}_{1}$ sesquidiploids, having at least one pair of the Eruca genome. These traits thus were considered "E. vesicaria-derived traits." After bolting, 19 morphological traits were further evaluated: pubescence and anthocyanin coloration of the stalk, flower buds, and pedicel; type of cauline leaves; petal color, shape, size, and vein color; filament color; anthocyanin coloration of the anthers; pollen presence; and type of inflorescence.

\subsection{Data analysis}

Each of the 19 morphological traits was classified into 2 to 4 grades for data analysis. If a trait was evaluated with two grades, it was classified as either 1 for B. rapa type or 2 for $E$. vesicaria type. If a trait was consisted of three grades, it was classified as 1 for $B$. rapa type, 3 for $E$. vesicaria type, and 2 for the intermediate type, and for the traits that were consisted of four grades, they were rated on a scale from 1 to 4,1 and 4 corresponding to $B$. rapa and $E$. vesicaria types, respectively, and 2 and 3 to intermediate $B$. rapa and $E$. vesicaria types or $\mathrm{F}_{1}$ type, respectively.

These numerically converted traits were subjected to Spearman's rank correlation analysis using BellCurve for Excel (Social Survey Research Information Co., LTD., Shinjuku, Japan). In cluster analysis, each numerical value was simply replaced with nucleobases: 1 for A, 2 for T, 3 for G, and 4 for $C$ to render a virtual DNA sequence and were then analyzed by maximum parsimony method using MEGA X (Kumar et al. 2018).

\section{Results}

\subsection{Backcross progenies of B. rapa $\times$ E. vesicaria hybrids}

Four $\mathrm{BC}_{1} \mathrm{~F}_{1}$ plants (Komeru $\mathrm{BC}_{1}$ hybrid line) were obtained as backcross progenies from 54 bud pollinations of intergeneric hybrids between $B$. rapa and $E$. vesicaria with the pollen parent, $B$. rapa, Misaki series (Table 1). Each of the four obtained $\mathrm{BC}_{1} \mathrm{~F}_{1}$ plants was further backcrossed with the same pollen donor to obtain the second backcross generation. Total of 2604 bud pollinations resulted in the formation of 534 siliquae, 161 out of which generated embryos suitable for embryo culture. Finally, 30 embryos germinated and 25 out of them developed into straight hybrid plants (Komeru $\mathrm{BC}_{2}$ hybrid line). Reciprocal crossing between $133 \mathrm{~B}$. rapa buds and pollen of $\mathrm{BC}_{1} \mathrm{~F}_{1}$ plants rendered 59 siliquae that generated 203 embryos, 105 out of which germinated and produced 68 reciprocal hybrid plants $\left(\mathrm{MKBC}_{1}\right.$ hybrid line). Overall regeneration efficiency of these backcrossed progenies based on the number of plants obtained to that of total buds pollinated was $6.7 \%, 7.4 \%, 1.0 \%$, and $51.1 \%$ for $\mathrm{F}_{1}, \mathrm{BC}_{1} \mathrm{~F}_{1}, \mathrm{BC}_{2} \mathrm{~F}_{1}$ straight cross, and $\mathrm{BC}_{2} \mathrm{~F}_{1}$ reciprocal cross, respectively (Table 1 ). 
Table 1

Results of intergeneric and back crosses between Brassica rapa and Eruca vesicaria

\begin{tabular}{|c|c|c|c|c|c|c|c|}
\hline \multicolumn{2}{|c|}{ Cross combination } & \multirow{2}{*}{$\begin{array}{l}\text { No. of flowers } \\
\text { pollinated }\end{array}$} & \multirow{2}{*}{$\begin{array}{l}\text { No. of siliques } \\
\text { setting }\end{array}$} & \multirow{2}{*}{$\begin{array}{l}\text { No. of ovules } \\
\text { cultured }\end{array}$} & \multirow{2}{*}{$\begin{array}{l}\text { No. of ovules } \\
\text { germinated }\end{array}$} & \multirow{2}{*}{$\begin{array}{l}\text { No. of }{ }^{z} \text { plants } \\
\text { obtained }\end{array}$} & \multirow{2}{*}{$\begin{array}{l}\text { Planty } \\
\text { yield } \\
\text { efficiency }\end{array}$} \\
\hline ૫ & ( & & & & & & \\
\hline \multicolumn{8}{|c|}{$F_{1}$ generation } \\
\hline B. rapa & E. vesicaria & 15 & 7 & $210^{x}$ & 1 & 1 & 6.7 \\
\hline \multicolumn{8}{|c|}{$\mathrm{BC}_{1} \mathrm{~F}_{1}$ generation } \\
\hline Komeru $\mathrm{F}_{1}$ & B. rapa & 54 & 7 & $4^{w}$ & 4 & 4 & 7.4 \\
\hline \multicolumn{8}{|c|}{$\mathrm{BC}_{2} \mathrm{~F}_{1}$ generation (straight cross) } \\
\hline $\begin{array}{l}\text { Komeru } \\
\mathrm{BC}_{1}-1\end{array}$ & B. rapa & 572 & 84 & $108^{w}$ & 13 & 10 & 1.7 \\
\hline $\begin{array}{l}\text { Komeru } \\
\mathrm{BC}_{1}-2\end{array}$ & & 689 & 42 & 23 & 13 & 12 & 1.7 \\
\hline $\begin{array}{l}\text { Komeru } \\
\mathrm{BC}_{1}-3\end{array}$ & & 471 & 257 & 16 & 3 & 3 & 0.6 \\
\hline $\begin{array}{l}\text { Komeru } \\
\mathrm{BC}_{1}-4\end{array}$ & & 872 & 151 & 14 & 1 & 0 & 0.0 \\
\hline Total & & 2604 & 534 & 161 & 30 & 25 & 1.0 \\
\hline \multicolumn{8}{|c|}{$\begin{array}{l}\mathrm{BC}_{2} \mathrm{~F}_{1} \text { generation (reciprocal } \\
\text { cross) }\end{array}$} \\
\hline \multirow[t]{4}{*}{ B. rapa } & $\begin{array}{l}\text { Komeru } \\
\mathrm{BC}_{1}-1\end{array}$ & 39 & 37 & $141^{\mathrm{w}}$ & 70 & 44 & 112.8 \\
\hline & $\begin{array}{l}\text { Komeru } \\
\mathrm{BC}_{1}-2\end{array}$ & 43 & 3 & 4 & 3 & 2 & 4.7 \\
\hline & $\begin{array}{l}\text { Komeru } \\
\mathrm{BC}_{1}-3\end{array}$ & 30 & 4 & 4 & 3 & 2 & 6.7 \\
\hline & $\begin{array}{l}\text { Komeru } \\
\mathrm{BC}_{1}-4\end{array}$ & 21 & 15 & 54 & 29 & 20 & 95.2 \\
\hline Total & & 133 & 59 & 203 & 105 & 68 & 51.1 \\
\hline \multicolumn{8}{|c|}{${ }^{\mathrm{z}}$ Number of individuals that reached the potting stage } \\
\hline \multicolumn{8}{|c|}{${ }^{\mathrm{y}}($ No. of plants obtained / No. of flowers pollinated $) \times 100$} \\
\hline
\end{tabular}

\subsection{Diversity of morphological traits in $\mathrm{BC}_{1} \mathrm{~F}_{1}$ and $\mathrm{BC}_{2} \mathrm{~F}_{1}$ generations}

Morphological traits of plants belonging to the $\mathrm{BC}_{1} \mathrm{~F}_{1}$ and $\mathrm{BC}_{2} \mathrm{~F}_{1}$ generations are shown in Fig. 2. $\mathrm{B}$. rapa inflorescences had no pubescence or anthocyanin coloration (Fig. 2a), and inflorescences of $\mathrm{BC}_{1} \mathrm{~F}_{1}$ plants, however, had little to no pubescence, similar to those of $B$. rapa (Fig. $2 \mathrm{~b}$ ), whereas those of $E$. vesicaria had a dense pubescence and anthocyanin coloration, especially in the floral buds (Fig. $2 \mathrm{C}$ ). Anthocyanin coloration of $\mathrm{BC}_{1} \mathrm{~F}_{1}$ plants was observed in both leaf veins and petioles when these plants were grown at $5^{\circ} \mathrm{C}$ (Fig. $2 \mathrm{~d}$ ). Petals of $B$. rapa were monochromatic yellow, while those of $E$. vesicaria were cream-colored with dark purple veins. $\mathrm{BC}_{1} \mathrm{~F}_{1}$ plants had intermediate-sized yellow petals with red veins and red blotches (Fig. 2e, f). Leaves of $B$. rapa were entire-spatulateshaped, having neither pubescence nor anthocyanin coloration, leaves of $E$. vesicaria were lyrate-pinnatipartite-shaped with visible pubescence and anthocyanin coloration and those of four $\mathrm{BC}_{1} \mathrm{~F}_{1}$ plants had a lyrate-pinnatilobate shape (Fig. $2 \mathrm{~g}$ ). Placenta in a siliqua had one row of ovules in $B$. rapa and two rows of ovules in E. vesicaria, whereas that of $\mathrm{BC}_{1} \mathrm{~F}_{1}$ plants had one row of ovules at the distant part and two rows in the middle (Fig. $2 \mathrm{~h}$ ). Cauline leaves wrapped around the stem of $B$. rapa but were unrolled in $E$. vesicaria. Four $\mathrm{BC}_{1} \mathrm{~F}_{1}$ plants had rolled cauline leaves, while one plant had one unrolled cauline leaf and no cauline leaf in E. vesicaria (Fig. 2i).

Since efficiency of $\mathrm{BC}_{2} \mathrm{~F}_{1}$ regeneration was very low, presence of a pre-fertilization barrier was presumed. Pollination of ten pistils of four $\mathrm{BC}_{1} \mathrm{~F}_{1}$ plants using $B$. rapa pollen induced callose deposition within pollen tubes that was observed under a fluorescence microscope. Furthermore, pollen tubes of $B$. rapa reached ovules in all four $\mathrm{BC}_{1} \mathrm{~F}_{1}$ plants, indicating that all four $\mathrm{BC}_{1} \mathrm{~F}_{1}$ had no pre-fertilization barrier (Fig. 2j). 
$\mathrm{BC}_{2} \mathrm{~F}_{1}$ displayed variation in morphological traits in both backcrosses. Petals of $\mathrm{BC}_{2} \mathrm{~F}_{1}$ were almost of the same size as those of $B$. rapa and very similar to those of $\mathrm{BC}_{1} \mathrm{~F}_{1}$. Petal shape, however, varied greatly: from broadly obovate such as those of $B$. rapa, through obovate, like those of $E$. vesicaria. Petal coloration also varied from monochromatic yellow (yellow petals and veins), through yellow with either red veins and red blotches or orange veins; however, various combinations of these traits were observed (Fig. $2 \mathrm{k}$ ). In $\mathrm{F}_{1}, \mathrm{BC}_{1} \mathrm{~F}_{1}$, and $\mathrm{BC}_{2} \mathrm{~F}_{1}$ generations, shading of petals with red blotches was associated with red veins only but not with yellow or orange veins. Interestingly, one $\mathrm{BC}_{2} \mathrm{~F}_{1}$ plant had red sectors in its yellow monochromatic petals (Fig. 2l). Although the species belonging to the Brassicaceae family generally have indeterminate inflorescences, some of the $\mathrm{BC}_{2} \mathrm{~F}_{1}$ plants had determinate inflorescences in which corymbs were composed of several flowers (Fig. $2 \mathrm{~m}$ ). Furthermore, although all $\mathrm{BC}_{1} \mathrm{~F}_{1}$ plants had either lyrately or pinnately incised leaves, all the $\mathrm{BC}_{2} \mathrm{~F}_{1}$ plants had various leaf shapes such as entire-spatulate, lyrate-pinnatipartite, and lyrate-pinnatilobate. Pubescence and anthocyanin coloration of leaves were also observed in some backcrossed plants (Fig. 2 n). Examination of chromosomes of pollen mother cells in the first meiotic metaphase of $\mathrm{BC}_{2} \mathrm{~F}_{1}$ revealed the presence of multiple univalent chromosomes in the majority of the plants (Fig. 20).

Incidence of major morphological traits observed in parental plants and their $\mathrm{F}_{1}, \mathrm{BC}_{1} \mathrm{~F}_{1}$, and $\mathrm{BC}_{2} \mathrm{~F}_{1}$ generations are summarized in Table 2. All the 19 morphological traits that are distinct between $B$. rapa and $E$. vesicaria were classified as either absence or presence, $B$. rapa-or $E$. vesicaria-type, or as a difference in color. When totally 20 strait and 62 reciprocal crosses of $B_{2} F_{1}$ plants that had grown to the flowering stage were examined, most of the $F_{1}$ and $\mathrm{BC}_{1} \mathrm{~F}_{1}$ plants exhibited more similar traits to $E$. vesicaria than to $B$. rapa. On the contrary, the second backcross generation, $\mathrm{BC}_{2} \mathrm{~F}_{1}$, displayed more $B$. rapa-like traits: $5 \%, 20 \%$, and $75 \%$ of the straight crossings had entire leaves, lobed leaves, or incised leaves, respectively, whereas $79 \%$ and $9.7 \%$ of the reverse crossings had entire and incised leaves, respectively. Leaf margin lobation was entire in $B$. rapa, incised in $E$. vesicaria, and incised in both $\mathrm{F}_{1}$ and $\mathrm{BC}_{1} \mathrm{~F}_{1}$ generations. $E$. vesicaria-like traits were segregated in reciprocal backcross progenies, suggesting the occurrence of recombination events. No progenies were obtained for pungency taste and the presence of stalk pubescence. 
Table 2

Incidence of major morphological traits observed in Brassica rapa, Eruca vesicaria, their intergeneric hybrids $\left(\mathrm{F}_{1}\right)$, and $\mathrm{BC}_{1} \mathrm{~F}_{1}$, $\mathrm{BC}_{2} \mathrm{~F}_{1}$ obtained using straight and reciprocal crosses

\begin{tabular}{|c|c|c|c|c|c|c|c|c|}
\hline \multicolumn{3}{|l|}{ Morphological characteristics } & \multirow{3}{*}{$\begin{array}{l}\text { B. rapay } \\
(-)\end{array}$} & \multirow{3}{*}{$\begin{array}{l}\text { E. vesicaria }{ }^{\mathrm{x}} \\
(-)\end{array}$} & \multirow{3}{*}{$\begin{array}{l}F_{1} \\
(1)\end{array}$} & \multirow{3}{*}{$\begin{array}{l}\mathrm{BC}_{1} \mathrm{~F}_{1} \\
\text { (4) }\end{array}$} & \multicolumn{2}{|l|}{$\mathrm{BC}_{2} \mathrm{~F}_{1}$} \\
\hline \multirow[t]{2}{*}{$\left(n^{z}\right)$} & & & & & & & Straight & Reciprocal \\
\hline & & & & & & & $(20)$ & $(62)$ \\
\hline \multirow{3}{*}{\multicolumn{2}{|c|}{ Pungency of leaf }} & absence & 100 & 0 & 0 & 25.0 & 95.0 & 77.4 \\
\hline & & weak & 0 & 0 & 0 & 75.0 & 0 & 12.9 \\
\hline & & strong & 0 & 100 & 100 & 0 & 5.0 & 9.7 \\
\hline \multirow{3}{*}{\multicolumn{2}{|c|}{ Sesame-like scent of leaf }} & absence & 100 & 0 & 0 & 25.0 & 85.0 & 96.8 \\
\hline & & weak & 0 & 0 & 0 & 75.0 & 15.0 & 3.2 \\
\hline & & strong & 0 & 100 & 100 & 0 & 0 & 0 \\
\hline \multirow[t]{8}{*}{ Anthocyanin pigmentation of } & \multirow[t]{2}{*}{ leaf } & absence & 100 & 0 & 0 & 75.0 & 90.0 & 96.8 \\
\hline & & presence & 0 & 100 & 100 & 25.0 & 10.0 & 3.2 \\
\hline & \multirow[t]{2}{*}{ stem } & absence & 100 & 0 & 0 & 75.0 & 40.0 & 75.8 \\
\hline & & presence & 0 & 100 & 100 & 25.0 & 60.0 & 24.2 \\
\hline & \multirow[t]{2}{*}{ bud } & absence & 100 & 0 & 0 & 75.0 & 95.0 & 98.4 \\
\hline & & presence & 0 & 100 & 100 & 52.0 & 5.0 & 1.6 \\
\hline & \multirow[t]{2}{*}{ pedicel } & absence & 100 & 0 & 0 & 0 & 75.0 & 93.5 \\
\hline & & presence & 0 & 100 & 100 & 100 & 25.0 & 6.5 \\
\hline \multirow[t]{6}{*}{ Pubescence of } & \multirow[t]{2}{*}{ leaf } & absence & 100 & 0 & 0 & 100 & 95.0 & 98.4 \\
\hline & & presence & 0 & 100 & 100 & 0 & 5.0 & 1.6 \\
\hline & \multirow[t]{2}{*}{ stem } & absence & 100 & 0 & 0 & 0 & 100 & 98.4 \\
\hline & & presence & 0 & 100 & 100 & 100 & 0 & 1.6 \\
\hline & \multirow[t]{2}{*}{ bud } & absence & 100 & 0 & 0 & 75.0 & 90.0 & 98.4 \\
\hline & & presence & 0 & 100 & 100 & 25.0 & 10.0 & 1.6 \\
\hline \multirow[t]{4}{*}{ Color of } & \multirow[t]{2}{*}{ filament } & yellow & 100 & 0 & 0 & 0 & 50.0 & 91.9 \\
\hline & & red & 0 & 100 & 100 & 100 & 50.0 & 8.1 \\
\hline & \multirow[t]{2}{*}{ anther } & yellow & 100 & 0 & 0 & 0 & 65.0 & 90.3 \\
\hline & & red & 0 & 100 & 100 & 100 & 35.0 & 9.7 \\
\hline \multirow{3}{*}{\multicolumn{2}{|c|}{ Lobation of leaf margin }} & absence & 100 & 0 & 0 & 0 & 5.0 & 79.0 \\
\hline & & weak & 0 & 0 & 0 & 0 & 20.0 & 11.3 \\
\hline & & strong & 0 & 100 & 100 & 100 & 75.0 & 9.7 \\
\hline \multirow[t]{4}{*}{ Type of } & \multirow[t]{2}{*}{ cauline } & B. rapa & 100 & 0 & 0 & 75.0 & 90.0 & 98.4 \\
\hline & & E. vesicaria & 0 & 100 & 100 & 25.0 & 10.0 & 1.6 \\
\hline & \multirow[t]{2}{*}{ petal } & B. rapa & 100 & 0 & 100 & 100 & 40.0 & 58.1 \\
\hline & & E. vesicaria & 0 & 100 & 0 & 0 & 60.0 & 41.9 \\
\hline \multirow[t]{4}{*}{ Petal } & color & yellow & 100 & 0 & 0 & 100 & 90.0 & 95.2 \\
\hline & & lemon & 0 & 0 & 100 & 0 & 10.0 & 4.8 \\
\hline & & cream & 0 & 100 & 0 & 0 & 0 & 0 \\
\hline & vein color & yellow & 100 & 0 & 0 & 0 & 40.0 & 85.5 \\
\hline
\end{tabular}

${ }^{\mathrm{z}}$ Number of individuals that reached flowering

${ }^{\mathrm{y}}$ Recurrent parent

${ }^{\mathrm{x}}$ Nonrecurrent parent 


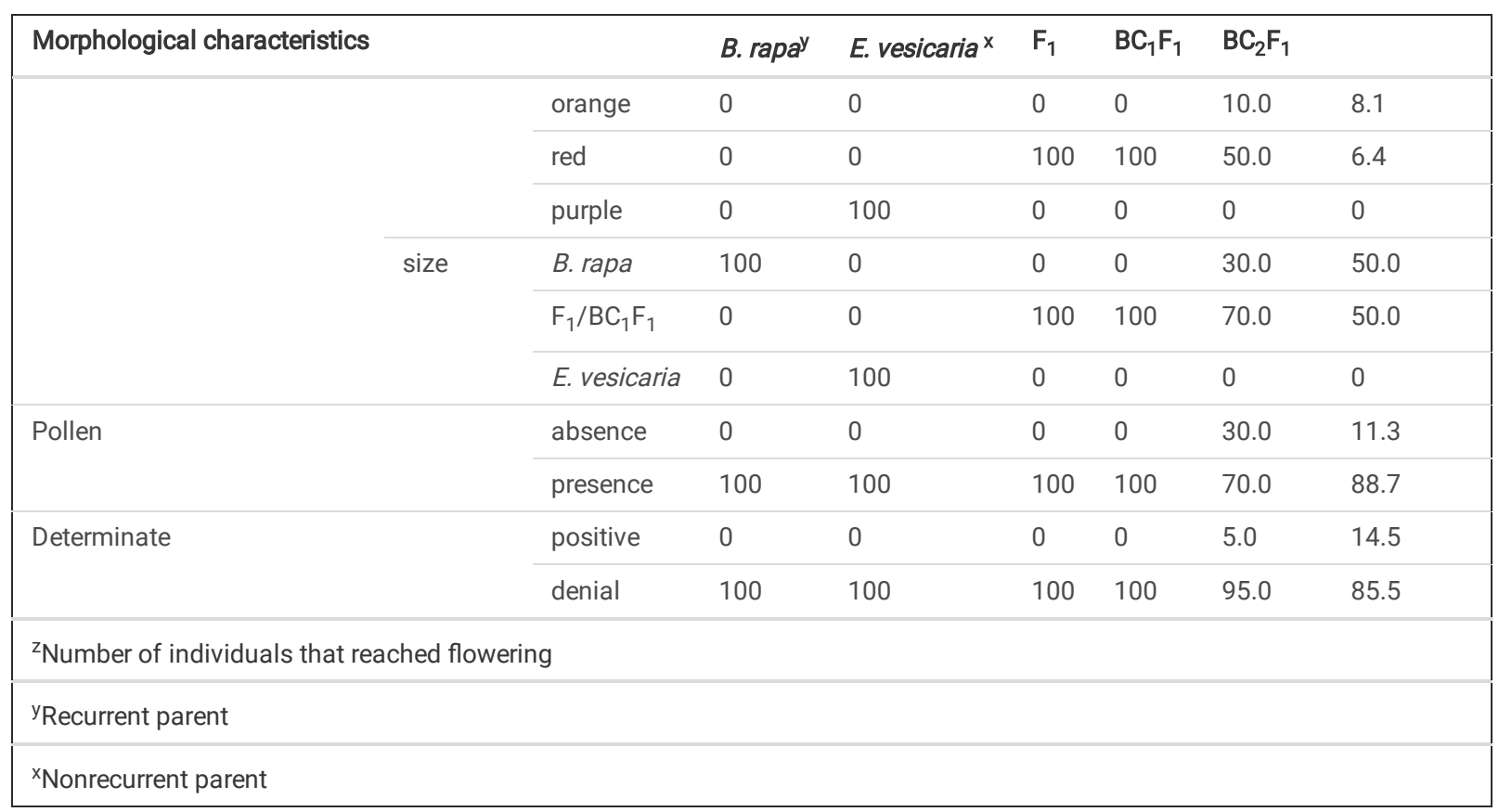

Diversity of the selected 19 morphological traits among the crossing parents $B$. rapa, $E$. vesicaria, and their hybrid and backcross progenies were analyzed in a series by applying the maximum parsimony (Fig. 3). When the breeding parental species were placed at both ends, an $\mathrm{F}_{1}$ progeny of $B$. rapa $\times E$. vesicaria, Komeru $\mathrm{F}_{1}$, was located next to $E$. vesicaria, while four $\mathrm{BC}_{1} \mathrm{~F}_{1}$ hybrids, Komeru $\mathrm{BC}_{1}-1-4$, were located next to Komeru $\mathrm{F}_{1}$. Komeru $\mathrm{BC}_{2}$ series, the second backcross generation of a straight cross, lay closer to $E$. vesicaria and $F_{1}$, whereas $M_{K B C}$ series, a reciprocal cross generation, resided between $B C_{1} F_{1}$ and $B$. rapa. In the reciprocal cross series, $20 \mathrm{BC}_{2} \mathrm{~F}_{1}$ plants clustered with $\mathrm{B}$. rapa and $8 \mathrm{BC}_{2} \mathrm{~F}_{1}$ plants belonged to another adjacent cluster, indicating that these plants may represent introgression lines bearing alien genes. In addition, six straight cross progenies formed a joint cluster, though, in other $\mathrm{BC}_{2} \mathrm{~F}_{1}$ generations, multiple clusters were formed, regardless if $\mathrm{BC}_{1} \mathrm{~F}_{1}$ individuals were used as parents or reciprocal crossings.

\subsection{GSL composition of $\mathrm{BC}_{1} \mathrm{~F}_{1}$ and $\mathrm{BC}_{2} \mathrm{~F}_{1}$ generations}

Leaf GSL composition varied between $B$. rapa and $E$. vesicaria plants: $B$. rapa contained glucoiberin, gluconapin, glucoalyssin, glucobrassicanapin, glucobrassicin, 4-methoxyglucobrassicin, and neoglucobrassicin, while $E$. vesicaria contained glucoerucin, glucoraphanin, glucosativin, and 4-

hydroxyglucobrassicin (Supplementary Table 1). Interestingly, all plants belonging to the $F_{1}, B_{1} F_{1}$, and $B C_{2} F_{1}$ generations contained all GSLs detected in both parental species but their amounts varied among each generation.

\subsection{Correlation between GSL composition and morphological traits of B. rapa, $E$. vesicaria, and their hybrid and backcross progenies}

Spearman's rank correlation analysis was applied to the analyzed morphological traits and GSL composition of intergeneric crossbred progenies of $B$. rapa and $E$. vesicaria. As shown in Table 3 , although the coefficients widely ranged from -0.39 to 0.73 , strong positive correlations were recorded between glucosativin and the sesame-like taste (0.73) and intermediate ones between glucoerucin, an E. vesicaria-specific GSL, and the sesame-like taste (0.51) and also between glucosativin on one side and pubescence on the stalk (0.53) and anthocyanin pigmentation of buds $(0.51)$, filaments $(0.60)$, and anthers $(0.57)$ on the other side. Interestingly, none of the morphological traits correlated with glucoraphanin.

Table 3 Spearman's rank correlation coefficients for morphological traits and amount of major glucosinolate species in the leaves of Brassica rapa, Eruca vesicaria, their intergeneric hybrids $\left(\mathrm{F}_{1}\right)$, and $\mathrm{BC}_{1} \mathrm{~F}_{1}, \mathrm{BC}_{2} \mathrm{~F}_{1}$ backcross straight and reciprocal cross progenies 


3 carbon 4 carbon side-chains $\quad 5$ carbon side-chains

Glucoiberin Glucoerucin Glucoraphanin Gluconapin Progoitrin Glucosativin Gluco- Gluco- Glucob

\begin{tabular}{|c|c|c|c|c|c|c|c|c|c|c|}
\hline \multirow{3}{*}{ Taste } & & & & & & & & alyssın & brassic & \\
\hline & pungent & -0.18 & 0.08 & 0.18 & 0.07 & 0.07 & $0.23^{*}$ & 0 & -0.08 & -0.18 \\
\hline & $\begin{array}{l}\text { sesame- } \\
\text { like }\end{array}$ & $-0.28^{\star \star}$ & $0.51^{\star \star}$ & 0.19 & $0.22^{\star *}$ & 0.11 & $0.73^{\star \star}$ & $0.31^{\star *}$ & -0.06 & $-0.21^{*}$ \\
\hline \multicolumn{2}{|l|}{ Leaf shape } & -0.18 & $0.34^{\star \star}$ & 0.25 & 0 & -0.03 & $0.29^{\star *}$ & $0.27^{\star}$ & -0.15 & $-0.29^{* *}$ \\
\hline \multirow{4}{*}{$\begin{array}{l}\text { Anthocyanin } \\
\text { pigmentation } \\
\text { of }\end{array}$} & leaf & $-0.29 * *$ & $0.38^{\star *}$ & 0.05 & -0.03 & 0.01 & $0.41^{* *}$ & 0.17 & -0.14 & -0.14 \\
\hline & stalk & -0.03 & 0.16 & 0.08 & 0.02 & -0.03 & 0.17 & 0.11 & -0.08 & $-0.33^{* \star}$ \\
\hline & bud & -0.1 & 0.28 & 0.09 & -0.02 & -0.09 & $0.51^{\star *}$ & 0.08 & -0.13 & $-0.28^{\text {*ᄎ }}$ \\
\hline & pedicel & -0.30 ** & 0.23 & 0.17 & 0.06 & 0.05 & $0.40^{\text {** }}$ & 0.05 & -0.06 & $-0.39^{* x}$ \\
\hline \multirow{3}{*}{$\begin{array}{l}\text { Pubescence } \\
\text { of }\end{array}$} & leaf & 0.02 & $0.21^{\star *}$ & $0.34^{\star *}$ & -0.08 & -0.08 & $0.26^{*}$ & 0.08 & -0.14 & 0 \\
\hline & stalk & $-0.35^{\star \star}$ & $0.40^{\star *}$ & 0.03 & 0.09 & 0.17 & $0.53^{\text {** }}$ & $0.30^{\star \star}$ & -0.07 & $-0.28^{\text {*ᄎ }}$ \\
\hline & bud & -0.16 & 0.12 & $0.22^{*}$ & 0.02 & 0.04 & 0.18 & 0.09 & -0.03 & -0.12 \\
\hline \multicolumn{2}{|l|}{ Type of cauline } & -0.27 & $0.27^{\star}$ & 0.19 & 0.01 & -0.1 & $0.47^{\star *}$ & 0 & -0.2 & $-0.21^{*}$ \\
\hline \multirow[t]{4}{*}{ Petal } & color & -0.16 & $0.21^{*}$ & 0.15 & -0.17 & -0.1 & $0.30^{\star \star}$ & 0.03 & -0.17 & -0.1 \\
\hline & $\begin{array}{l}\text { vein } \\
\text { color }\end{array}$ & -0.17 & $0.29^{\star *}$ & 0.17 & 0.19 & 0 & $0.49^{\star *}$ & $0.47^{\star \star}$ & 0.01 & $-0.28^{* \star}$ \\
\hline & size & 0.02 & 0.06 & 0.08 & -0.08 & 0.03 & 0.04 & 0.1 & -0.13 & $-0.31^{* *}$ \\
\hline & shape & 0.11 & -0.19 & 0.21 & -0.06 & -0.11 & -0.12 & -0.2 & -0.02 & 0 \\
\hline \multirow[t]{2}{*}{ Color of } & filament & $-0.21^{*}$ & $0.39^{\star *}$ & 0.21 & 0.1 & -0.02 & $0.60^{\star *}$ & $0.44^{\star *}$ & -0.06 & $-0.30^{* \star}$ \\
\hline & anther & -0.1 & $0.36^{* *}$ & $0.21^{*}$ & 0.16 & 0 & $0.57^{\star \star}$ & $0.40^{\star *}$ & -0.01 & -0.16 \\
\hline \multicolumn{2}{|l|}{ Pollen } & 0.15 & 0.06 & 0.09 & -0.04 & 0.09 & -0.06 & 0.01 & 0 & 0.02 \\
\hline \multicolumn{2}{|l|}{ Determinate } & 0.06 & -0.05 & -0.01 & 0.13 & -0.13 & -0.13 & 0.01 & 0.11 & 0.15 \\
\hline
\end{tabular}

\section{Discussion}

Generation of intergenic hybrids between B. rapa (A genome) as the ovule parent and $E$. vesicaria (E genome) as the pollen parent has been previously reported by Mizushima (1950a, b), but further progenies have not been successfully produced either through selfing or by backcrossing thereafter (FitzJohn et al. 2007; Kaneko et al. 2009). In the present study, however, we successfully generated synthetic amphidiploid $B_{1} F_{1}$ generation and $B C_{2} F_{1}$ generation by backcrossing $B$. rapa. Although the obtained regeneration efficiency was lower than $10 \%$ for both $\mathrm{BC}_{1} \mathrm{~F}_{1}$ and the $\mathrm{BC}_{2} \mathrm{~F}_{1}$ straight cross generation as many ovules did not grow and embryo abortion occurred at the time of $\mathrm{BC}_{2} \mathrm{~F}_{1}$ production, $\mathrm{BC}_{2} \mathrm{~F}_{1}$ reciprocal crosses resulted in more than $50 \%$ regeneration efficiency and no pre-fertilization barrier in stigmata of $\mathrm{BC}_{1} \mathrm{~F}_{1}$ plants was detected. A low number of embryos that could be used for embryo rescue implies that postfertilization barriers might exist, since in spite that $\mathrm{BC}_{1} \mathrm{~F}_{1}$ stigmata have actually been pollinated by $B$. rapa pollen to produce $\mathrm{BC}_{2} \mathrm{~F}_{1}$, some ovules died or did not grow enough to make embryos worth rescuing. Kaneko and Bang (2014) previously showed that repeated backcrossing in both interspecific and intergeneric hybrids of Brassicaceae resulted in varying levels of male/female infertility or occurrence of pre-/post-fertilization barriers, depending on the combination of species, and that the overall seed fertility of the hybrids was quite low. Therefore, sesquidiploids would not be easily utilized as ovule parents in intergeneric crossing. Generation of $\mathrm{BC}_{2} \mathrm{~F}_{1}$ plants through backcrossing of sesquidiploid parents, however, would be quite useful for obtaining AGIL, MAAL, and MASL (Kaneko et al. 2009; Kaneko and Bang 2014). Actually, reciprocal crossbreeding of sesquidiploids as pollen parents aided in a successful introduction of a blackleg disease-resistance gene from B. rapa to B. napus (Yu et al. 2012). Results obtained in the present study also suggest that reciprocal $\mathrm{BC}_{2} \mathrm{~F}_{1}$ crossing may be a promising strategy for introducing genetically stable heterologous alien genes or generating various types of chromosomeintrogression lines.

In the present study, the analysis of intergeneric hybrid progeny obtained by crossing between $B$. rapa and $E$. vesicaria showed that morphological traits of $E$. vesicaria were dominantly expressed in the $\mathrm{F}_{1}$ generation, while some of the $B$. rapa-specific traits phenotypically appeared in the $\mathrm{BC}_{2} \mathrm{~F}_{1}$ generation with various combinations of parents' traits. In addition, this hybridization event generated various plants featured by novel traits not previously found in either 
parent such as red or orange veins, absence of pollen, or determinate inflorescences. In particular, red blotches observed in the center of corolla of the $F_{1}$ and $\mathrm{BC}_{1} \mathrm{~F}_{1}$ plants represented a novel trait that Brassica spp. do not possess. The red-expressing region appears to overlap with the nectar guide area, containing UV-absorbing flavonoids (Sasaki and Takahashi 2002). However, proportions of plants bearing these traits differed greatly between the straight and reciprocal hybridizations. An increased diversity of morphological traits was recorded in interspecific hybrid progenies of $B$. oleracea var. alboglabra and $B$. rapa var. purpurea in the shape and color of inflorescences, leaves, stalks, and several other characteristics (Zhang et al. 2016). Furthermore, in the $\mathrm{BC}_{2} \mathrm{~F}_{1} \mathrm{population}$ derived from a cross between $B$. napus with yellow flowers and Orychophragmus violaceus with large purple flowers, a unique individual, having yellow flowering petals, while being red before opening, was obtained (Ding et al. 2013). In alloplasmic $\mathrm{F}_{7}\left(\mathrm{BC}_{1} \mathrm{~F}_{6}\right)$ progenies of a cross between $E$. vesicaria and $B$. rapa, plants whose stamens were changed into petals were recorded (Matsuzawa et al. 1999). In the present study, however, no such plants were observed.

In this study, all the four $\mathrm{BC}_{1} \mathrm{~F}_{1}$ plants showed a similar phenotypic appearance in both petal characteristics and leaf shape as the $\mathrm{F}_{1}$ ovule parent. Because morphological traits of $\mathrm{F}_{1}(\mathrm{AAEE})$ and $\mathrm{BC}_{1} \mathrm{~F}_{1}(\mathrm{AAE})$ are considered to result from the addition of the $E$ genome, both alien chromosome-addition lines are expected to have similar phenotypes, while $\mathrm{BC}_{2} \mathrm{~F}_{1}$ displayed not only characteristics specific to their parents but also novel characteristics such as yellow flower vein color. Mizushima (1950a) reported up to eight divalent chromosomes during metaphase of $F_{1}(A E)$ hybrids, which indicates that the $A$ and $E$ genomes can pair, implying occurrence of heterozygote translocation between chromosomes of these two genomes in the hybrid progeny. A dynamic chromosomal structural modification due to polyvalent chromosome formation could occur not only in E-derived gene expression but also in A-genome gene expression. These genomic alterations may trigger interactions among newly introduced or rearranged genes, which might result in the emergence of novel phenotypes.

Among 4-carbon side-chains, glucoerucin, glucoraphanin, gluconapin, and progoitrin that are produced in the biosynthetic pathway of aliphatic GSLs, gluconapin was the major GSL found in B. rapa. By contrast, E. vesicaria contained glucoerucin, glucoraphanin, and glucosativin that are synthesized from glucoerucin (Bennett et al. 2002; Bell and Wagstaff 2014, 2019; Ishida et al. 2014; Osada and Aoyagi 2014; Fechner et al. 2018). Both $F_{1}$ and BC $F_{1}$ hybrids obtained in the present study contained GSLs synthesized by both parental species. If these hybrids contained the $E$. vesicaria genome, compounds produced in the downstream part of the biosynthetic pathway would also accumulate. As several factors that control the GSL biosynthesis have been elucidated (Ishida et al. 2014), it is highly plausible that expression patterns of transcription factors related to the biosynthetic pathway of aliphatic GSLs in Brassica species that possess alien chromosomes may be regulated.

Some morphological traits of $E$. vesicaria were dominantly inherited in the $\mathrm{BC}_{2} \mathrm{~F}_{1}$ population that was derived from an intergeneric hybridization between $B$. rapa and E. vesicaria. The relationship between morphological traits and GSL composition observed in this study revealed that sesame-like taste was strongly correlated with glucosativin but weakly correlated with glucoerucin, suggesting that sesame flavor may be related to the biosynthetic pathways of these compounds. This supports the fact that glucosativin itself is a typical flavor agent of crushed fresh arugula leaves (Bennett et al. 2002; Fechner et. al. 2018; Raffo et al. 2018; Bell and Wagstaff 2019). In a previously reported sensory analysis, E. vesicaria accessions with a broad range of GSL profiles, glucosativin, and its dimer did not correlate with bitterness, while glucosativin was positively correlated with an earthy flavor and its dimer was positioned between earthy and pungent attributes, but it was not significantly correlated with any specific sensation (Bell et al. 2017). However, the authors did not mention "sesame-like taste or flavor." Thus, it would be difficult to determine a specific GSL profile from particular morphological traits expressed in the $\mathrm{BC}_{2} \mathrm{~F}_{1}$ generation.

In the present study, we successfully generated intergeneric progenies from a cross between $B$. rapa and $E$. vesicaria up to the $\mathrm{BC}_{2} \mathrm{~F}_{1} \mathrm{generation} \mathrm{Although}$ $\mathrm{BC}_{2} \mathrm{~F}_{1}$ progenies exhibited few characteristics of $E$. vesicaria, new traits such as red blotches and red and orange veins in petals as well as some characteristic E. vesicaria GSLs could be introduced into the $B$. rapa gene pool. These findings demonstrate that repeated backcrossing can be a promising method to introduce useful and/or unique alien traits into closely related species after obtaining intergeneric cross hybrids.

\section{Declarations}

\section{Acknowledgments}

The authors would like to thank Pro. Bang at Utsunomiya University, Mr. Serizawa at the Nagano Vegetable and Ornamental Crops Experiment Station, Mr. Yoshida and Mr. Tomita at Kanagawa Agricultural Technology Center, Ms. Miyazawa and Ms. Kai at Kanagawa Prefectural Institute of Public Health. We would like to extend our special thanks to the technical staffs, Ms. Takahashi and Ms. Nakata at Kanagawa Agricultural Technology Center. The authors would like to thank Enago (www.enago.jp) for the English language review.

\section{Funding}

Competing Interests: The authors have no relevant financial or non-financial interests to disclose.

\section{Author Contribution Statement}

Aiko Kaminishi: developed the plants, conducted the experiments, and analyzed the data. Fumika Miyohashi: partly participated in the experiments. Nobuhiro Kita: conceived the project, designed the research, and critically reviewed and improved the final manuscript.

\section{References}

1. Agnihotri A, Gupta V, Lakshmikumaran MS, Shivanna KR, Prakash S, Jagannathan V (1990) Production of Eruca-Brassica hybrids by embryo rescue. Plant Breed 104:281-289. https://doi.org/10.1111/j.1439-0523.1990.tb00437.x. 
2. Bennet, RN, Mellon FA, Botting NP, Eagles J, Rosa EAS, Williamson G (2002) Identification of the major glucosinolate (4-mercaptobutyl glucosinolate) in leaves of Eruca sativa L. (salad rocket). Phytochemi 61:25-30. https://doi.org/10.1016/S0031-9422(02)00203-0.

3. Bell L, Wagstaff C (2014) Glucosinolates, myrosinase hydrolysis products and flavonols found in Rocket (Eruca sativa and Diplotaxis tenuifolia). J Agric Food Chem 62:4481-4492. https://doi.org/10.1021/jf501096x.

4. Bell L, Methven L, Signore A, Oruna-Concha MJ, Wagstaff C (2017) Analysis of seven salad rocket (Eruca sativa) accessions: The relationships between sensory attributes and volatile and non-volatile compounds. Food Chem 218:181-191. https://doi.org/10.1016/j.foodchem.2016.09.076.

5. Bell L, Wagstaff C (2019) Rocket science: A review of phytochemical \& health-related research in Eruca \& Diplotaxis species. Food Chem X 1:100002. https://doi.org/10.1016/j.fochx.2018.100002.

6. Ding L, Zhao Z-g, Ge X-H, Li Z-Y (2013) Intergeneric addition and substitution of Brassica napus with different chromosomes from Orychophragmus violaceus: Phenotype and cytology. Sci Hortic 164:303-309. https://doi.org/10.1016/j.scienta.2013.09.043.

7. Fechner J, Kaufmann M, Herz C, Eisenshmidt D, Lamy E, Kroh LW, Hanschen FS (2018) The major glucosinolate hydrolysis product in rocket (Eruca sativa L.), sativin, is 1,3-thiazepane-2-thione: Elucidation of structure, bioactivity, and stability compared to other rocket isothiocyanates. Food Chem 261:57-65. https://doi.org/10.1016/j.foodchem.2018.04.023.

8. FitzJohn RG, Armstrong TT, Newstrom-Lloyd LE, Wilton AD, Cochrane M (2007) Hybridisation within Brassica and allied genera: evaluation of potential for transgene escape. Euphytica 158:209-230. https://doi.org/10.1007/s10681-007-9444-0.

9. Friedt W, Tu J, Fu T (2018) Academic and economic importance of Brassica napus rapeseed. In: Liu S, Snowdon R, Chalhoub B (ed) The Brassica napus genome. Springer Nature, Switzerland AG, Cham, pp 1-20. https://doi.org/10.10007/978-3-319-43694-4.

10. Ishida M, Okuyama Y, Takahata Y, Kaizuma N (1995) Varietal diversity of seed glucosinolates content and its composition in Japanese winter rape (Brassica napus L.). Jpn J Breed 45:357-364. https://doi.org/10.1270/jsbbs1951.45.357

11. Ishida M, Kakizaki T, Ohara T, Morimitsu Y (2011) Development of a simple and rapid extraction method of glucosinolates from radish roots. Breed Sci 61:208-211. https://doi.org/10.1270/jsbbs.61.208.

12. Ishida M, Hara M, Fukino N, Kakizaki T, Morimitsu Y (2014) Glucosinolate metabolism, functionality and breeding for the improvement of Brassicaceae vegetables. Breed Sci 64:48-59. https://doi.org/10.1270/jsbbs.64.48

13. Kaneko Y, Bang SW, Matsuzawa Y (2009) 11 Distant hybridization. In: Gupta SK (ed) Biology and breeding crucifers. Taylor \& Francis Group, New York, pp 207-247.

14. Kaneko Y, Bang SW (2014) Interspecific and intergeneric hybridization and chromosomal engineering of Brassicaceae crops. Breed Sci 64:14-22. https://doi.org/10.1270/jsbbs.64.14.

15. Kaminishi A, Miyohashi F, Kikuchi S, Koba T, Yoshida M, Kita N (2017). Glucosinolate and isothiocyanate composition in an intergeneric hybrid generated by crossing Brassica rapa L. with Eruca sativa Mill. Hort Res 16:265-271. https://doi.org/10.2503/hrj.16.265.

16. Kim SJ, Jin S, Ishii G (2004) Isolation and structural elucidation of 4-( $\beta$-D-Glucopyranosyldisulfanyl) butyl glucosinolate from leaves of rocket salad (Eruca sativa L.) and its antioxidative activity. Biosci Biotechnol Biochem 68:2444-2450. https://doi.org/10.1271/bbb.68.2444.

17. Kumar S, Stecher G, Li M, Knyaz C, Tamura K (2018) MEGA X: Molecular evolutionary genetics analysis across computing platforms. Mol Biol Evol 35:1547-1549. https://doi.org/10.1093/molbev/msy096.

18. Matsuzawa, Y., Mekiyanon S, Kaneko Y, Bang SW, Wakui K, Takahata Y (1999) Male sterility in alloplasmic Brassica rapa L. carrying Eruca sativa cytoplasm. Plant Breed 118:82-84. https://doi.org/10.1046/j.1439-0523.1999.118001082.x.

19. Mizushima U (1950a) Karyogenetic studies of species and genus hybrids in the tribe Brassiceae of Cruciferae. Tohoku J Agric Res 1:1-14.

20. Mizushima U (1950b) On several artificial allopolyploides obtained in the tribe Brassiceae of Cruciferae. Tohoku J Agric Res 1:15-27.

21. Murashige T, Skoog F (1962) A revised medium for rapid growth and bio assays with tobacco tissue cultures. Physiol Plant 15:473-497. https://doi.org/10.1111/j.1399-3054.1962.tb08052.x.

22. Osada S, Aoyagi Y (2014) Level of glucosinolates in Brassicaceae vegetables harvested during autumn and winter in Japan. J Integr Stud Diet Habits 25:121-130. https://doi.org/10.2740/jisdh.25.121.

23. Raffo A, Masci M, Moneta E, Nicoli S, del Pulgar JS, Paoletti F (2018) Characterization of volatiles and identification of odor-active compounds of rocket leaves. Food Chem 240:1161-1170. https://doi.org/10.1016/j.foodchemi.2017.08.009.

24. Sasaki K, Takahashi T (2002) A flavonoid from Brassica rapa flower as the UV-absorbing nectar guide. Phytochemistry 61:339-343. https://doi.org/10.1016/S0031-9422(02)00237-6

25. Velasco P, Rodriguez VM, Francisco M, Cartea ME, Soengas P (2017) Genetics and breeding of Brassica crops. In: Merillon JM, Ramawat KG (ed) Glucosinolates. Springer International Publishing AG. Cham, pp 61-86. https://doi.org/10.1007/978-3-319-25462-3.

26. Yu F, Lydiate DJ, Gugel RK, Sharpe AG, Rimmer SR (2012) Introgression of Brassica rapa subsp. sylvestris blackleg resistance into B. napus. Mol Breed 30:1495-1506. https://doi.org/10.1007/s11032-012-9735-6.

27. Zhang X, Liu T, Li X, Duan M, Wang J, Qiu Y, Wang H, Song J, Shen D (2016) Interspecific hybridization, polyploidization, and backcross of Brassica oleracea var. alboglabra with B. rapa var. purpurea morphologically recapitulate the evolution of Brassica vegetables. Sci Rep 6:18618.

https://doi.org/10.1038/srep18618.

\section{Figures}




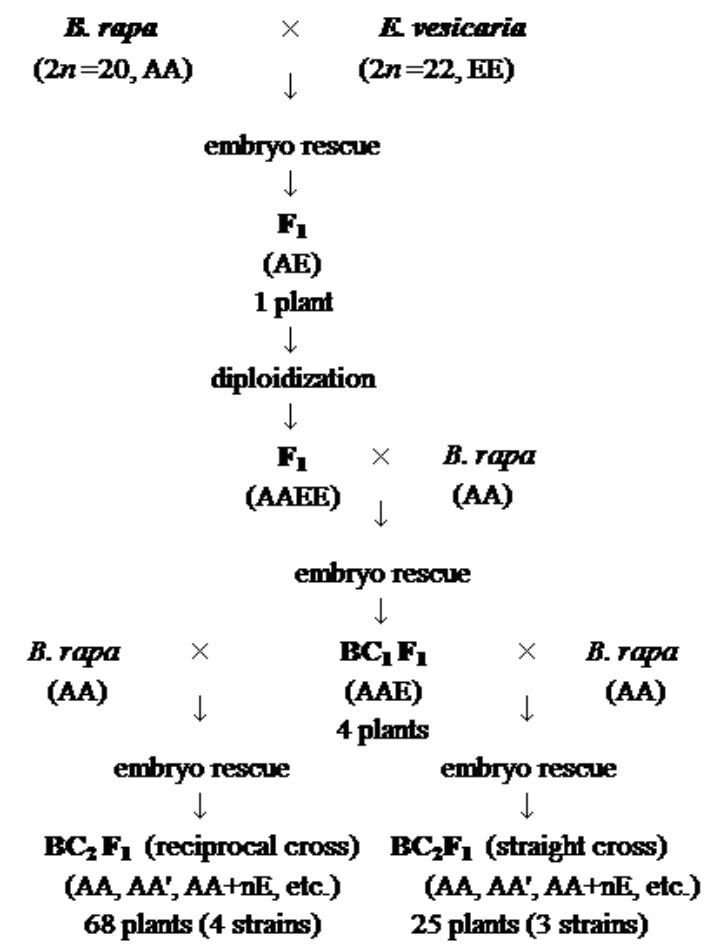

Figure 1

Backcrossing scheme for the hybridization between Brassica rapa and Eruca vesicaria. Structure of each genome, including progenies and the number of hybrid lines obtained are shown in parenthesis and at the figure bottom

2

Figure 2

Morphological traits of flowers, buds, petals, habitus, leaves, pods, and chromosomes of intergeneric hybrid BC1F1 and BC2F1 plants obtained from backcrossing with Brassica rapa and Eruca vesicaria. Inflorescences of B. rapa (a), Komeru BC1-2 hybrid (b), and E. vesicaria (c); habitus of Komeru BC1-1 hybrid (d); corolla (e), petal (f), leaf shape (g), placenta (h), and proximal end of a cauline leaf (i) of B. rapa (left), four intergeneric BC1F1 hybrids (center), and E. vesicaria (right) (note that the second plant from left of four intergeneric BC1F1 hybrid plants has an unrolled cauline leaf); pollen tube growth toward ovules of an intergeneric hybrid BC1F1 (j); corollas of B. rapa (left), four BC2F1 hybrids ( $\mathrm{k}$ ), and of another BC2F1 plant(I); determinate inflorescence of a $\mathrm{BC} 2 \mathrm{~F} 1$ plant $(\mathrm{m})$; leaf shapes of six BC2F1 hybrids $(\mathrm{n})$; and chromosome behavior in metaphase I of a BC2F1 hybrid (o) 


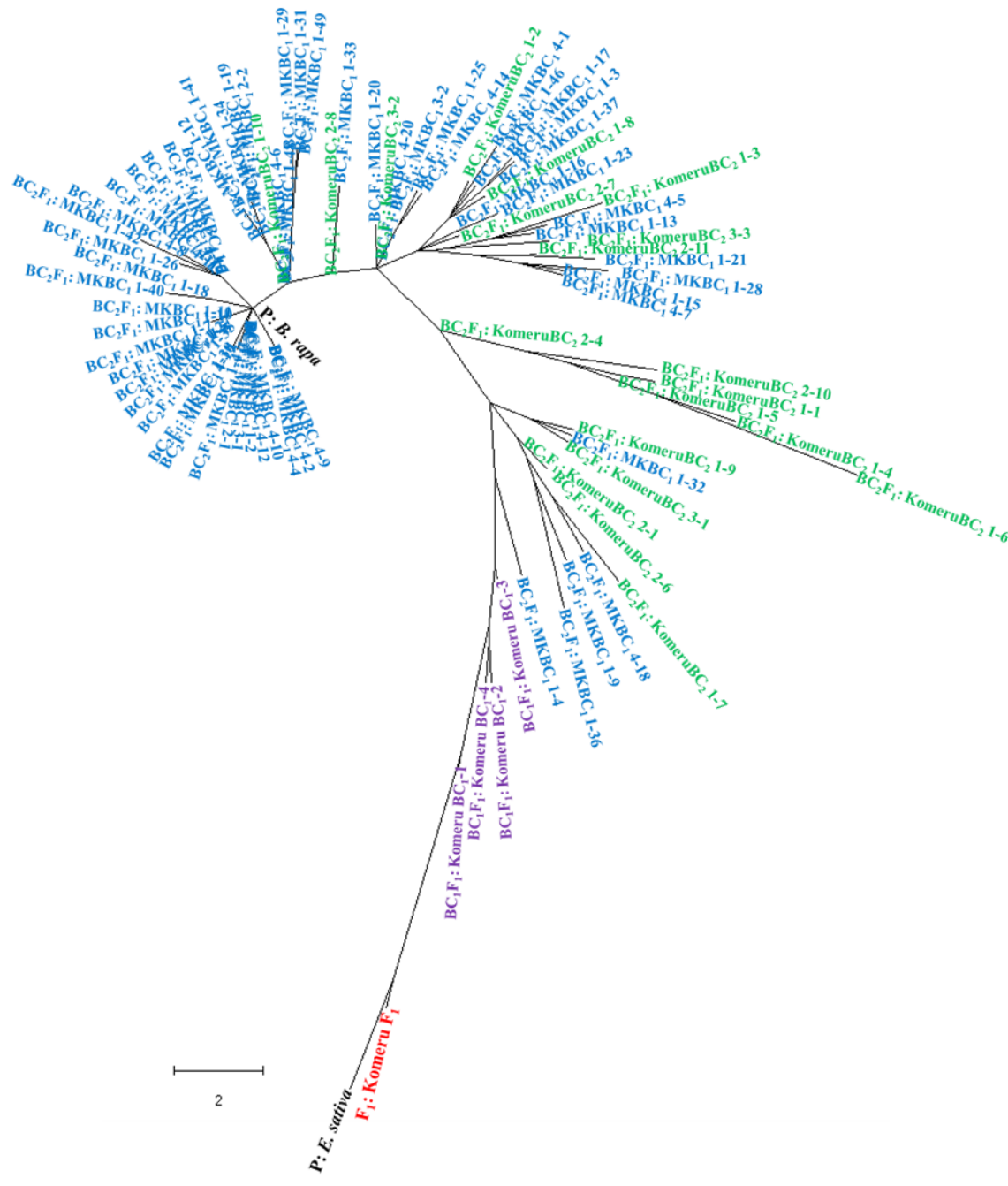

\section{Figure 3}

Cladogram of totally 89 plants of Brassica rapa, Eruca vesicaria, and their intergeneric hybrid progenies based on taste and morphological traits and constructed using the maximum parsimony algorithm. Each morphological trait was classified into two to four grades, according to its presence/absence, type, or level and was replaced with nucleobase letters A, G, T or C to mimic nucleotide sequences (Kumar et al. 2018). Recurrent parent, B. rapa; nonrecurrent parent, E. vesicaria; F1, Komeru F1 (red); BC1F1, Komeru BC1 (purple); straight cross BC2F1, Komeru BC2 (green); reciprocal cross BC2F1, MKBC1 (blue)

\section{Supplementary Files}

This is a list of supplementary files associated with this preprint. Click to download.

- Kaminishi2021Supplementarytable.docx 